\title{
Can VEGFR-3 be a better tumor marker for breast cancer than CA 15-3?
}

\author{
Monika Zajkowska1, Ewa Gacuta², Emilia Lubowicka³, Maciej Szmitkowski ${ }^{4}$ \\ and Sławomir Ławickisø
}

'Department of Neurodegeneration Diagnostics, Medical University of Bialystok, Białystok, Poland; '2Department of Perinatology, Medical University of Bialystok, Białystok, Poland; ${ }^{3}$ Department of Esthetic Medicine, Medical University of Bialystok, Białystok, Poland; ${ }^{4}$ Department of Biochemical Diagnostics, Medical University of Bialystok, Białystok, Poland; ${ }^{5}$ Department of Population Medicine and Civilization Diseases Prevention, Medical University of Bialystok, Białystok, Poland

\begin{abstract}
Vascular Endothelial Growth Factor Receptor 3 (VEGFR-3) is a very important factor which promotes lymphangiogenesis not only in physiological but also in pathological processes in which we can include neoplasia. The aim of this study was to analyze the plasma concentrations and diagnostic utility of this parameter in comparison and in combination with CA 15-3 in breast cancer (BC) patients and in relation to the control groups. The study included 120 breast cancer and 60 control patients ( 28 with benign breast tumors and 32 healthy women). Plasma levels of VEGFR-3 were determined by an Enzyme-Linked Immunosorbent Assay (ELISA), and those of CA 15-3 by a Chemiluminescent Microparticle Immuno Assay (CMIA). Differences in concentrations of both of the tested parameters were statistically significant when breast cancer patients were compared to the control groups. VEGFR-3 had higher values of sensitivity (SE), specificity (SP), predictive value of a positive (PPV) and negative test result (NPV) in the whole BC group (90\%; 98.33\%; 99.08\%; $83.10 \%$, respectively) and, more importantly, in the early stages of BC, than CA 15-3. VEGFR-3 was also a better parameter in terms of statistically significant Area Under Curve (0.9656) in the whole group and at all BC stages (I-IV), but a maximum range was obtained for the combination of VEGFR-3 and CA 15-3 (0.9710). The combined analysis of VEGFR-3 and CA 15-3 provides hope that a new BC diagnostic panel may be developed in the future.
\end{abstract}

Key words: Fms-related tyrosine kinase 4; diagnostic utility; Area Under Curve; Receiver Operating Characteristics

Received: 17 September, 2019; revised: 19 December, 2019; accepted: 31 January, 2020; available on-line: 11 March, 2020

छe-mail: slawicki@umb.edu.pl

Acknowledgements of Financial Support: This research was fi nanced by Grants for Medical University of Białystok (N/ST/ MN/17/002/2207, N/ST/MN/18/001/2207) from the Polish Ministry of Science and Higher Education.

Abbreviations: $B C$, Breast Cancer; VEGFR-3, Vascular Endothelial Growth Factor Receptor 3; CA 15-3, Cancer Antigen 15-3; ELISA Enzyme-linked Immunosorbent Assay; CMIA, Chemiluminescent Microparticle Immunoassay; AUC, Area Under Curve; ROC, Receiver Operating Characteristics; SE, Sensitivity; SP, Specificity; PPV, Positive Predictive Value; NPV, Negative Predictive Value

\section{INTRODUCTION}

The ACS (American Cancer Society) estimates that 609,640 deaths occurred from cancer in 2018 in the United States, which corresponds to almost 1700 deaths per day (Siegel et al., 2018). From among all malignancies, breast cancer $(\mathrm{BC})$ is the most frequent tumor type occurring in women worldwide (Torre et al., 2015; Oeffinger et al., 2015). To combat cancer in the most effective way, its early detection and prevention is needed. Therefore, a search for new markers that would detect the transformation of malignant cells as soon as possible is vital (Zajkowska et al., 2016).

Nowadays, biochemical detection of $\mathrm{BC}$ is mainly restricted to CA 15-3. Prognostic relevance of this marker is supported by a number of studies. However, it was shown that it has insufficient diagnostic sensitivity at less advanced stages of this type of cancer (Harris et al., 2007; Lawicki et al., 2016). That is why, a search for some new markers that would show high diagnostic usefulness is continuing. Angiogenesis and lymphangiogenesis are two very important processes which are involved in tumor progression and creation of metastases. They can also determine the local development of cancer (Egeblad \& Werb 2002). We hope that new candidates for tumor markers could be VEGF family members and their receptors, such as VEGFR-3.

There are three commonly known receptors for VEGFs (VEGFR-1, VEGFR-2, VEGFR-3). Each of them has the possibility of binding selected factors which belong to the VEGF family on the basis of different affinities and selectivity (Carmeliet et al., 2013; Caballero et al., 2017). VEGFR-3 is mainly expressed in the lymphoid endothelial cells and regulates lymphangiogenesis in response to VEGF-C and VEGF-D (Alitalo \& Carmeliet 2002). Activation of VEGFR-3 by its ligands, as well as subsequent activation of the intracellular tyrosine kinase domain, stimulates the proliferation of lymphatic endothelial cells. Lymphangiogenesis using the VEGFR-3/VEGF-C/VEGF-D axis has been demonstrated in numerous in vivo and in vitro studies (Weryńska et al., 2009; Achen \& Stacker, 2006).

The aim of the study presented here was to investigate the plasma levels, the diagnostic utility (sensitivity, specificity, predictive values of positive and negative test results) and power (ROC curve analysis) of VEGFR-3 and a comparative tumor marker CA $15-3$ in breast cancer detection. In this study, control groups were constituted of healthy volunteers and women with benign breast lesions. This ma0y provide a more accurate reflection of the current female population. The data obtained in this study may prove the usefulness of the analyzed parameters (separately and together) in the detection of BC.

\section{MATERIALS AND METHODS}

Patients. The study included 120 breast cancer patients (BC) diagnosed by the oncology group (Table 1). The patients were treated at the Department of Oncol- 
ogy, Medical University, Bialystok, Poland. Tumor classification and staging were conducted in accordance with the International Union Against Cancer Tumor-NodeMetastasis (UICC-TNM) classification. Breast cancer histopathology was established in all cases by tissue biopsy of the mammary tumor or following surgery from the tumor tissues (all patients with adenocarcinoma ductale). The pretreatment staging procedures included: physical and blood examinations, mammography, mammary ultrasound scanning, breast core biopsies and chest X-rays.

In addition, radioisotopic bone scans, examination of bone marrow aspirates, and brain and chest CT scans were performed when necessary. None of the patients had received chemo- or radiotherapy prior to blood sample collection.

The control group included 60 patients: 28 with benign breast tumors (adenoma, fibroadenoma) and 32 healthy, untreated women who underwent mammary gland examination performed by a gynecologist prior to blood sample collection (Table 1). In addition, mammary ultrasound scanning was performed in all cases. Benign breast tumor histopathology was established in all cases by tissue biopsy of the mammary tumor or after surgery.

For each of the patients qualified for the control group, the exclusion criteria, such as: active infections and symptoms of an infection (both bacterial and viral), other comorbidities which can affect cytokine concentrations (respiratory diseases, digestive tract diseases) or systemic diseases, such as lupus, rheumatoid arthritis or collagenosis, were applied.

Biochemical analyses. Venous blood samples were collected from each patient into an EDTA tube (S-Monovette, SARSTEDT, Germany), centrifuged $1000 \times g$ for $15 \mathrm{~min}$ at $2-8^{\circ} \mathrm{C}$ to obtain plasma samples and stored at $-85^{\circ} \mathrm{C}$ until assayed. The tested parameters were measured with the enzyme-linked immunosorbent assay (ELISA) (VEGFR-3 - Affymetrix, Inc., Santa Clara, CA, USA), or the chemiluminescent microparticle immunoassay (CMIA) (CA 15-3 - Abbott, Chicago, IL, USA) according to the manufacturer's protocols. In case of ELISA, duplicate samples were assessed for each standard, control, and sample, according to the manufacturer's protocols.

Statistical analysis. Statistical analysis was performed with STATISTICA 12.0 software (StatSoft, Tulsa, OK, USA). Preliminary statistical analysis (using the ShapiroWilk test) revealed that the tested parameters and tumor marker levels did not follow a normal distribution. Consequently, statistical analysis between the groups was performed using the U-Mann Whitney test, the KruskalWallis test and a multivariate analysis of various data by the post-hoc Dwass-Steele-Crichlow-Flinger test. The data were presented as a median and a range. Diagnostic sensitivity (SE), specificity (SP), and the predictive values of positive and negative test results (PPV and NPV, respectively) were calculated by using cut-off values which were calculated by the Youden's index (as a criterion for selecting the optimum cut-off point) from combined control group, and for each of the tested parameters were as follows: VEGFR-3 - $45.19 \mathrm{ng} / \mathrm{mL}$; CA 15-3-18.45 $\mathrm{U} / \mathrm{mL}$. We also defined the receiver-operating characteristics (ROC) curve for all of the tested parameters and tumor markers. Construction of the ROC curves was performed using the GraphRoc program for Windows (Windows, Royal, AR, USA), and the areas under the ROC curve (AUC) were calculated to evaluate the diagnostic accuracy and to compare AUC for VEGFR-3 separately and in combination with the commonly used tumor marker (CA 15-3). Statistically significant differences were defined as comparisons resulting in $p<0.05$.
Table 1. Characteristics of breast cancer patients and control groups: benign breast tumor and healthy women.

\begin{tabular}{|c|c|c|c|}
\hline \multicolumn{3}{|c|}{ Study group } & \multirow{2}{*}{$\begin{array}{l}\text { Number of } \\
\text { patients }\end{array}$} \\
\hline \multirow{9}{*}{ 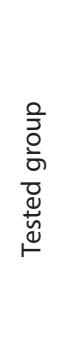 } & Breast cancer patients & $\begin{array}{l}\text { Adenocarcino- } \\
\text { ma ductale }\end{array}$ & \\
\hline & Median age (range) & & $58(39-83)$ \\
\hline & Tumor stage & I & 38 \\
\hline & & II & 41 \\
\hline & & III & 20 \\
\hline & & IV & \\
\hline & Menopausal status: & & \\
\hline & - premenopausal & & 21 \\
\hline & - postmenopausal & & 99 \\
\hline \multirow{11}{*}{$\begin{array}{l}\text { 음 } \\
\text { 음 } \\
\frac{0}{0} \\
\frac{0}{0} \\
0\end{array}$} & Benign breast tumor & & 28 \\
\hline & & Adenoma & 10 \\
\hline & & Fibroadenoma & 18 \\
\hline & Median age (range) & & $48(36-71)$ \\
\hline & Menopausal status: & & \\
\hline & - premenopausal & & 10 \\
\hline & - postmenopausal & & 18 \\
\hline & Healthy women & & 32 \\
\hline & Median age (range) & & $49(33-73)$ \\
\hline & Menopausal status: & & \\
\hline & - postmenopausal & & 18 \\
\hline
\end{tabular}

\section{RESULTS}

Table 2 shows the plasma levels of VEGFR-3 and CA 15-3 in patients with breast cancer and in controls. Concentrations of both parameters in the whole cancer group were statistically significantly higher when compared with the whole control group, the benign breast tumor group and the healthy women group (in all cases $p<0.05)$. Also, at all stages of cancer (I-IV), both parameters showed a statistical significance when compared to all controls (in all cases $p<0.05$ ).

Table 3 shows the sensitivity (SE), specificity (SP), positive predictive value (PPV) and negative predictive value (NPV) of VEGFR-3, CA 15-3 and their combination. We indicated that the SE of single tested parameters was higher for VEGFR-3 in the whole cancer group $(90 \%)$, and at stages I-IV of cancer $(84.21 \%$; $92.68 \%$; $85 \% ; 100 \%$, respectively). The diagnostic SP of the single tested parameters was also higher for VEGFR-3 $(98.33 \%)$. The same was true for the predictive value of a positive test result (PPV) in the whole group of $\mathrm{BC}$ patients $(99.08 \%)$ and at all stages of BC $(96.97 \% ; 97.44 \%$; $94.44 \% ; 95.45 \%$, respectively). The predictive value of a negative test result (NPV) was also higher for VEGFR-3 in the whole BC group $(83.10 \%)$, and at stages I-IV of BC (90.77\%; 95.16\%; 95.16\%; 100\%, respectively). A combined analysis of the tested parameter and CA 15-3 resulted in an increase in SE and NPV.

The ROC curve illustrates a relationship between the diagnostic SE and SP. The area under the ROC curve (AUC) indicates the clinical usefulness of a tumor marker and its diagnostic power. All data relating to the AUC's in the whole BC group is included in Table 4. Graphical versions of the ROC curve for VEGFR-3, CA 15-3 and their 
Table 2. Plasma levels of the tested parameter and CA 15-3 in patients with breast cancer and in control group.

\begin{tabular}{|c|c|c|c|}
\hline Groups tested & & $\begin{array}{l}\text { VEGFR-3 } \\
(\mathrm{ng} / \mathrm{mL})\end{array}$ & $\begin{array}{l}\text { CA 15-3 } \\
(\mathrm{U} / \mathrm{mL})\end{array}$ \\
\hline \multirow{5}{*}{$\begin{array}{l}\text { Breast cancer } \\
\text { Median } \\
\text { Range }\end{array}$} & I stage & $\begin{array}{l}86.47 \mathrm{a} / \mathrm{b} / \mathrm{c} / \mathrm{d} \\
17.50-133.55\end{array}$ & $\begin{array}{l}16.70 \mathrm{a} / \mathrm{c} / \mathrm{d} \\
6.20-50.30\end{array}$ \\
\hline & Il stage & $\begin{array}{l}95.59 \mathrm{a} / \mathrm{b} / \mathrm{c} \\
22.60-172.27\end{array}$ & $\begin{array}{l}16.90 \mathrm{a} / \mathrm{b} / \mathrm{c} / \mathrm{d} \\
4.40-48.10\end{array}$ \\
\hline & III stage & $\begin{array}{l}101.79 \mathrm{a} / \mathrm{b} / \mathrm{c} \\
25.76-174.52\end{array}$ & $\begin{array}{l}26.50 \mathrm{a} / \mathrm{b} / \mathrm{c} / \mathrm{d} \\
8.90-167.50\end{array}$ \\
\hline & IV stage & $\begin{array}{l}132.42 \mathrm{a} / \mathrm{b} / \mathrm{c} / \mathrm{d} \\
47.47-185.05\end{array}$ & $\begin{array}{l}45.10 \mathrm{a} / \mathrm{b} / \mathrm{c} / \mathrm{d} \\
18.50-250.00\end{array}$ \\
\hline & Total group & $\begin{array}{l}98.03 \mathrm{a} a / \mathrm{b} \\
17.50-185.05\end{array}$ & $\begin{array}{l}19.95 \mathrm{a} / \mathrm{b} / \mathrm{c} \\
4.40-250.00\end{array}$ \\
\hline \multirow{3}{*}{$\begin{array}{l}\text { Control group } \\
\text { Median } \\
\text { Range }\end{array}$} & Benign breast tumor & $\begin{array}{l}16.67 \\
7.37-104.05\end{array}$ & $\begin{array}{l}12.75 \\
4.00-20.70\end{array}$ \\
\hline & Healthy women & $\begin{array}{l}18.05 \\
4.79-42.91\end{array}$ & $\begin{array}{l}13.40 \\
6.30-28.40\end{array}$ \\
\hline & Total group & $\begin{array}{l}17.13 \\
4.79-104.05\end{array}$ & $\begin{array}{l}13.05 \\
4.00-28.40\end{array}$ \\
\hline
\end{tabular}

aStatistically significant when compared with benign breast tumor; ${ }^{\circ}$ Statistically significant when compared with healthy women; cStatistically significant when compared with the whole control group; dStatistically significant when BC patients at stage III or IV were compared with BC patients at stage I or II; Abbreviations: VEGFR-3, Vascular Endothelial Growth Factor Receptor 3; CA 15-3, Cancer Antigen 15-3.

combination in the whole group of BC is shown in Fig. 1. We noticed that the VEGFR-3 area under the ROC curve (0.9656) in the whole group of breast cancer was higher than CA 15-3. In case of all stages of BC, AUC was also higher for VEGFR-3 (0.9406; 0.9780; 0.9567; 0.9952, respectively). Combined analysis of the tested parameter and CA 15-3 resulted in an increase in AUC in all cases, and in the whole cancer group it has reached 0.9710 . The AUCs for the tested parameters, similarly as for the commonly used tumor markers, were statistically significantly larger in comparison to $\mathrm{AUC}=0.5$ (borderline of the diagnostic usefulness of the test) $(p<0.05$ in all cases).

\section{DISCUSSION}

Lymphangiogenesis belongs to one of the most crucial processes during tumor progression. VEGF (Vascular Endothelial Growth Factor) family members and their receptors have a direct effect on endothelial cell proliferation and migration. They are also potent stimulatory factors of those processes. Early diagnosis of cancer and determination of its stage allows to increase the survival

Table 3. Diagnostic criteria of the tested parameter and CA 15-3 in patients with breast cancer.

\begin{tabular}{|c|c|c|c|c|c|c|}
\hline \multirow{2}{*}{ Tested parameter } & \multirow{2}{*}{ Diagnostic criteria (\%) } & \multicolumn{5}{|c|}{ Breast cancer } \\
\hline & & I stage & Il stage & III stage & IV stage & Total group \\
\hline CA $15-3$ & $\begin{array}{l}\text { SE } \\
\text { SP } \\
\text { PPV } \\
\text { NPV }\end{array}$ & $\begin{array}{l}39.47 \\
95.00 \\
83.33 \\
71.25\end{array}$ & $\begin{array}{l}46.34 \\
95.00 \\
86.36 \\
72.15\end{array}$ & $\begin{array}{l}75.00 \\
95.00 \\
83.33 \\
91.94\end{array}$ & $\begin{array}{l}90.48 \\
95.00 \\
86.36 \\
96.61\end{array}$ & $\begin{array}{l}58.33 \\
95.00 \\
95.89 \\
53.27\end{array}$ \\
\hline VEGFR-3 & $\begin{array}{l}\text { SE } \\
\text { SP } \\
\text { PPV } \\
\text { NPV }\end{array}$ & $\begin{array}{l}84.21 \\
98.33 \\
96.97 \\
90.77\end{array}$ & $\begin{array}{l}92.68 \\
98.33 \\
97.44 \\
95.16\end{array}$ & $\begin{array}{l}85.00 \\
98.33 \\
94.44 \\
95.16\end{array}$ & $\begin{array}{l}100.00 \\
98.33 \\
95.45 \\
100.00\end{array}$ & $\begin{array}{l}90.00 \\
98.33 \\
99.08 \\
83.10\end{array}$ \\
\hline CA $15-3$ + VEGFR-3 & $\begin{array}{l}\text { SE } \\
\text { SP } \\
\text { PPV } \\
\text { NPV }\end{array}$ & $\begin{array}{l}86.84 \\
95.00 \\
91.67 \\
95.00\end{array}$ & $\begin{array}{l}97.56 \\
95.00 \\
93.02 \\
98.28\end{array}$ & $\begin{array}{l}100.00 \\
95.00 \\
86.96 \\
100.00\end{array}$ & $\begin{array}{l}100.00 \\
95.00 \\
87.50 \\
100.00\end{array}$ & $\begin{array}{l}95.00 \\
95.00 \\
97.44 \\
90.48\end{array}$ \\
\hline
\end{tabular}

Abbreviations: SE, Sensitivity; SP, Specificity; PPV, Positive Predictive Value; NPV, Negative Predictive Value; VEGFR-3, Vascular Endothelial Growth Factor Receptor 3; CA 15-3, Cancer Antigen 15-3. rate of women suffering from breast cancer by indicating effective treatment methods. Due to many reports regarding the usefulness of tumor markers not only in breast cancer, it is very important that the diagnosis is not limited to diagnostic imaging (Lawicki et al., 2013, Będkowska et al., 2017; Ławicki et al., 2016; Zajkowska et al., 2016).

In the study presented here we investigated the usefulness of VEGFR-3, separately and in combination with CA 15-3 (a commonly used tumor marker) in breast cancer patients, not only in the whole group of patients but also in particular cancer TNM stage groups (stages I, II, III and IV).

Statistically significant plasma overexpression and high gene expression of VEGFR-3 have been detected in patients suffering from many types of tumors, including breast cancer (Huang et al., 2014; Xia et al., 2016; Raica et al., 2011). We have demonstrated statistically significantly higher plasma concentrations of the tested parameter when compared to control groups. Unfortunately, we have found only one publication concerning plasma levels of VEGFR-3 in the breast (Bando et al., 2006), with the use of the same method. However, that study did not compare the concen- 
Table 4. Diagnostic criteria of ROC curve for the tested parameters at all stages of BC.

\begin{tabular}{|c|c|c|c|c|}
\hline \multirow{2}{*}{ Tested parameters } & \multicolumn{4}{|c|}{ ROC criteria in breast cancer (I stage) } \\
\hline & AUC & StE & 95\% C.I. (AUC) & $p(\mathrm{AUC}=0.5)$ \\
\hline CA $15-3$ & 0.6480 & 0.0610 & $(0.528-0.768)$ & 0.0153 \\
\hline VEGFR-3 & 0.9406 & 0.0238 & $(0.894-0.987)$ & $<0.001$ \\
\hline CA $15-3+$ VEGFR-3 & 0.9373 & 0.0275 & $(0.883-0.991)$ & $<0.001$ \\
\hline \multirow{2}{*}{ Tested parameters } & \multicolumn{4}{|c|}{ ROC criteria in breast cancer (II stage) } \\
\hline & AUC & StE & 95\% C.I. (AUC) & $p(\mathrm{AUC}=0.5)$ \\
\hline CA $15-3$ & 0.6967 & 0.0567 & $(0.586-0.808)$ & $<0.001$ \\
\hline VEGFR-3 & 0.9780 & 0.0134 & $(0.952-1.004)$ & $<0.001$ \\
\hline CA $15-3+$ VEGFR-3 & 0.9854 & 0.0100 & $(0.966-1.005)$ & $<0.001$ \\
\hline \multirow{2}{*}{ Tested parameters } & \multicolumn{4}{|c|}{ ROC criteria in breast cancer (III stage) } \\
\hline & AUC & StE & 95\% C.I. (AUC) & $p(\mathrm{AUC}=0.5)$ \\
\hline CA $15-3$ & 0.8692 & 0.0555 & $(0.760-0.978)$ & $<0.001$ \\
\hline VEGFR-3 & 0.9567 & 0.0226 & $(0.912-1.001)$ & $<0.001$ \\
\hline CA $15-3+$ VEGFR-3 & 0.9775 & 0.0131 & $(0.952-1.003)$ & $<0.001$ \\
\hline \multirow{2}{*}{ Tested parameters } & \multicolumn{4}{|c|}{ ROC criteria in breast cancer (IV stage) } \\
\hline & AUC & StE & 95\% C.I. (AUC) & $p(\mathrm{AUC}=0.5)$ \\
\hline CA $15-3$ & 0.9667 & 0.0165 & $(0.934-0.999)$ & $<0.001$ \\
\hline VEGFR-3 & 0.9952 & 0.0051 & $(0.985-1.005)$ & $<0.001$ \\
\hline CA $15-3+$ VEGFR-3 & 0.9976 & 0.0027 & $(0.992-1.003)$ & $<0.001$ \\
\hline \multirow{2}{*}{ Tested parameters } & \multicolumn{4}{|c|}{ ROC criteria in the whole breast cancer group } \\
\hline & AUC & StE & 95\% C.I. (AUC) & $p(\mathrm{AUC}=0.5)$ \\
\hline CA $15-3$ & 0.7573 & 0.0351 & $(0.688-0.826)$ & $<0.001$ \\
\hline VEGFR-3 & 0.9656 & 0.0129 & $(0.940-0.991)$ & $<0.001$ \\
\hline CA $15-3$ + VEGFR-3 & 0.9710 & 0.0119 & $(0.948-0.994)$ & $<0.001$ \\
\hline
\end{tabular}

p - statistically significantly larger AUC's compared to AUC $=0.5$. Abbreviations: AUC, Area Under Curve; ROC, Receiver Operating Characteristics; StE, Standard Error; 95\% C.I., 95\% Confidence Interval; VEGFR, Vascular Endothelial Growth Factor Receptor 3; CA 15-3, Cancer Antigen 15-3.

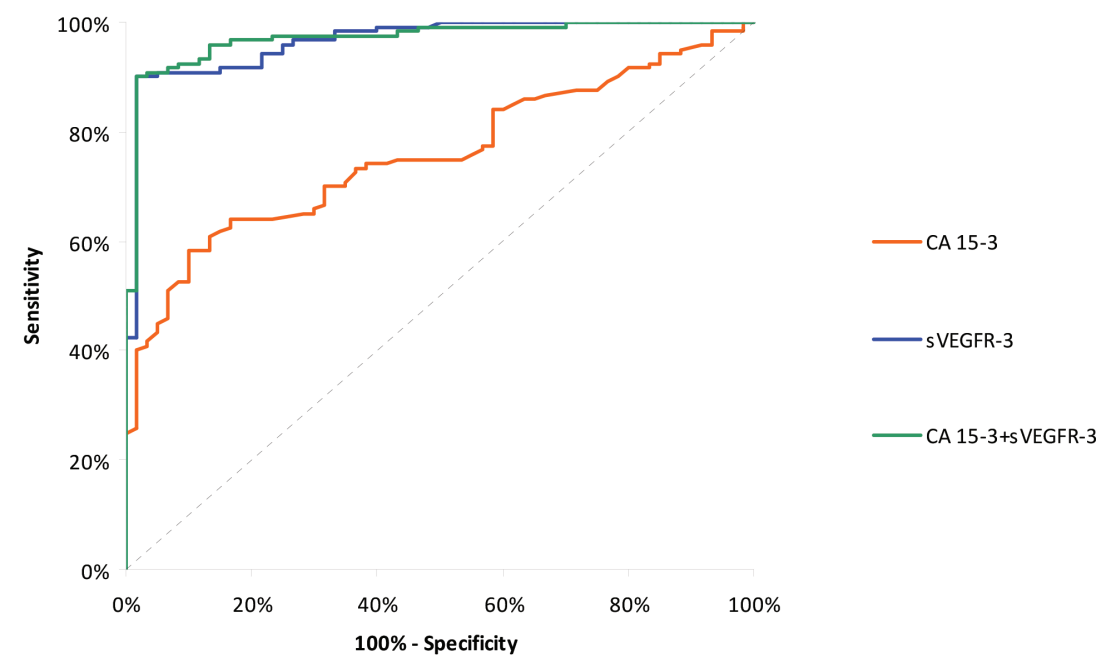

Figure 1. Diagnostic criteria of ROC curve for the tested parameters and in combination with CA 15-3 in the whole BC group.

trations in cancer patients and healthy subjects, but evaluated its association with prognosis for disease-free survival and overall survival of patients with primary breast cancer. However, that same study (Bando et al., 2006) has shown that the concentrations of VEGFR-3 in breast cancer pa- tient samples, using the ELISA method, were comparable to ours. We have also found a study employing a different method - immunohistochemistry in endometrial cancer (Yokoyama et al., 2000). We have compared the results of this work with ours due to the similar selection of control groups (not only healthy women, but also women with benign lesions). In that study the authors revealed that in healthy subject there in no expression of VEGFR-3, in endometrial hyperplasia there are $28 \%$ of patients with positive expression of this receptor, and in case of endometrial cancer - 57\%. In case of our study, the concentrations of VEGFR-3 were increasing with the stage of breast cancer, which may indicate its usefulness in determining the severity of the disease. However, confirmation of this relationship in a different type of cancer also indicates its low organ specificity, so VEGFR-3 could only be used in combination with another parameter, highly specific to the examined organ. 
Sensitivity (SE) measures the proportion of correctly identified positives. Specificity (SP) measures the proportion of correctly identified negatives. In this study, both of these parameters were the highest for VEGFR-3 in the whole group of breast cancer patients and at all stages of BC. Our results show that VEGFR-3 also has the highest PPV and NPV values for both tested parameters not only in the wholel group, but also at most stages of $\mathrm{BC}$ patients. To our knowledge, this work is the first to estimate not only the concentrations but also the diagnostic utility (SE, SP, PPV and NPV) of VEGFR-3. Due to that fact, we are not able to compare our results to the work of other authors.

The most important criterion for tumor markers is the $\mathrm{SE} / \mathrm{SP}$ diagram - the ROC curve. The diagnostic power (AUC) represents the overall accuracy of a test, with the value approaching 1.0 indicating a perfect SE and SP. Our results showed that VEGFR-3 had the highest AUC of all the tested parameters in the whole group of $\mathrm{BC}$ patients (0.9656) and at all stages of this cancer (IIV). Much lower results (AUC $=0.734$ ) were obtained for VEGFR-3 by other researchers (Huang et al., 2014). This discrepancy might be related to a different type of tumor (papillary thyroid carcinoma) used in their research.

Among all diagnostic usefulness assessments, our study is the only one which evaluates the diagnostic usefulness of VEGFR-3 in such a highly advanced way (combined analysis of VEGFR-3 with a commonly used tumor marker).

In future diagnosis, a combined analysis of the tested parameters with commonly used tumor markers (in case of BC - CA 15-3), may be the most proper way to improve the detection rate of tumors. This is related to the non-specific character of most of the other parameters. That is why these parameters should be only used in a panel to improve the sensitivity of the specific markers available to date.

\section{CONCLUSIONS}

Early detection of breast cancer in patients is of utter importance. Our results presented here indicate the usefulness and high diagnostic power of the tested parameter in detection of breast cancer. VEGFR-3 appeared to be a better candidate for cancer diagnostics (superior to the commonly used tumor marker - CA 15-3). Combined analysis of VEGFR-3 and CA 15-3 resulted in an increase in the SE and AUC values which provides hope for developing a new panel of biomarkers that may be used in the diagnosis of $\mathrm{BC}$ in the future.

\section{Conflicts of interest}

None declared.

\section{Ethics approval and informed consent}

This study was approved by the local Ethics Committee at the Medical University of Białystok (R-I$002 / 70 / 2015)$. All of the patients gave their informed consent for study participation.

\section{Ethical declaration}

This work was conducted in accordance with the Declaration of Helsinki (1964).

\section{Contribution Statement}

MZ conceived the idea for the study. MZ, SE, MSz contributed to the design of the research. All authors were involved in data collection and analyzed the data.
MZ coordinated funding for the project. All authors edited and approved the final version of the manuscript.

\section{REFERENCES}

Achen MG, Stacker SA (2006) Tumor lymphangiogenesis and metastatic spread-new players begin to emerge. Int J Cancer 119:17551760. https://doi.org/10.1002/ijc.21899

Alitalo K, Carmeliet P (2002) Molecular mechanisms of lymphangiogenesis in health and disease. Cancer Cell 1: 219-227. https://doi. org/10.1016/S1535-6108(02)00051-X.

Bando H, Weich HA, Horiguchi S, Funata N, Ogawa T, Toi M (2006) The association between vascular endothelial growth factor-C, its corresponding receptor, VEGFR-3, and prognosis in primary breast cancer: a study with 193 cases. Oncol Rep 15: 653-659

Będkowska GE, Gacuta E, Zajkowska M, Glażewska EK, Osada J, Szmitkowski M, Chrostek L, Dabrowska M, Lawicki S (2017) Plasma levels of MMP-7 and TIMP-1 in laboratory diagnostics and differentiation of selected histological types of epithelial ovarian cancers. J Ovarian Res 10: 39. https://doi.org/10.1186/s13048-0170338-z

Caballero B, Sherman SJ, Falk T (2017) Insights into the mechanisms involved in protective effects of VEGF-B in dopaminergic neurons. Parkinsons Dis 2017: 4263795. https://doi. org/10.1155/2017/4263795

Carmeliet P, Ruiz de Almodovar C, Carmen ReA (2013) VEGF ligands and receptors: implications in neurodevelopment and neurodegeneration. Cell Mol Life Sci 70: 1763-1778. https://doi.org/10.1007/ s00018-013-1283-7

Egeblad M, Werb Z (2002) New functions for the matrix metalloproteinases in cancer progression. Nat Rev Cancer 2: 161-174. https:// doi.org/10.1038/nrc745

Harris L, Fritsche H, Mennel R, Norton L, Ravdin P, Taube S, Somerfield MR, Hayes DF, Bast RC, American Society of Clinical Oncology (2007) American Society of Clinical Oncology 2007 update of recommendations for the use of tumor markers in breast cancer. J Clin Oncol 25: 5287-5312. https://doi.org/10.1200/ JCO.2007.14.2364.

Huang J, Li Y, Xue G, Zhang W, Li S, Zhang J, Wu J (2014) Value of VEGF-C, VEGF-D and VEGFR-3 levels combined with serum TSH in diagnosis of papillary thyroid carcinoma. Nan Fang Yi Ke Da Xиe Xиe Baо 34: 1814-1817, 1821

Ławicki S, Będkowska GE, Gacuta-Szumarska E, Szmitkowski M (2013) The plasma concentration of VEGF, HE4 and CA125 as a new biomarkers panel in different stages and sub-types of epithelial ovarian tumors. J Ovarian Res 6: 45. https://doi.org/10.1186/17572215-6-45

Ławicki S, Zajkowska M, Głażewska EK, Będkowska GE, Szmitkowski M (2016) Plasma levels and diagnostic utility of VEGF, MMP-9, and TIMP-1 in the diagnosis of patients with breast cancer. Onco Targets Ther 9: 911-919. https://doi.org/10.2147/OTT.S99959

Oeffinger KC, Fontham ET, Etzioni R, Herzig A, Michaelson JS, Shih YC, Walter LC, Church TR, Flowers CR, LaMonte SJ, Wolf AM, DeSantis C, Lortet-Tieulent J, Andrews K, Manassaram-Baptiste D, Saslow D, Smith RA, Brawley OW, Wender R, American Cancer Society (2015) Breast cancer screening for women at average risk: 2015 guideline update from the american cancer society. JAMA 314: 1599-1614. https://doi.org/10.1001/jama.2015.12783

Raica M, Cimpean AM, Ceausu R, Ribatti D (2011) Lymphatic microvessel density, VEGF-C, and VEGFR-3 expression in different molecular types of breast cancer. Anticancer Res 31: 1757-1764.

Siegel RL, Miller KD, Jemal A (2018) Cancer statistics, 2018. CA Cancer J Clin 68: 7-30. https://doi.org/10.3322/caac.21442

Torre LA, Bray F, Siegel RL, Ferlay J, Lortet-Tieulent J, Jemal A (2015) Global cancer statistics, 2012. CA Cancer J Clin 65: 87-108. https://doi.org/10.3322/caac.21262

Weryńska B, Dziegiel P, Jankowska R (2009) Role of lymphangiogenesis in lung cancer. Folia Histochem Cytobiol 47: 333-342. https://doi. org/10.2478/v10042-009-0090-3

Xia H, Shen J, Chen S, Huang H, Xu Y, Ma H (2016) Overexpression of VEGF-C correlates with a poor prognosis in esophageal cancer patients. Cancer Biomark 17: 165-170. https://doi.org/10.3233/ CBM-160627

Yokoyama Y, Sato S, Futagami M, Fukushi Y, Sakamoto T, Umemoto M, Saito Y (2000) Prognostic significance of vascular endothelial growth factor and its receptors in endometrial carcinoma. Gynecol Oncol 77: 413-418. https://doi.org/10.1006/gyno.2000.5802

Zajkowska M, Głażewska EK, Będkowska GE, Chorąży P, Szmitkowski M, Lawicki S (2016) Diagnostic power of vascular endothelial growth factor and macrophage colony-stimulating factor in breast cancer patients based on ROC analysis. Mediators Inflamm 2016: 5962946. https://doi.org/10.1155/2016/5962946 